\title{
Competitive Dynamics and Pricing Behavior in US Hotels: The Role of Co-location
}

\author{
Cathy A. Enz, Linda Canina, Zhaoping Liu \\ Cornell University
}

\begin{abstract}
Which hotels benefit from locating next to competitors? In this study of 14,995 hotels we provide evidence of both a price benefit and a detriment for specific hotels that co-locate next to other hotels. Relying on the theoretical framework of agglomeration economics, the results reveal that hotels that co-locate in the same geographic cluster with the highest quality segmented firms (luxury hotels) accrue a price premium compared to competitors in markets with larger proportions of lower-segmented competitors. The strongest price premiums were obtained by midscale hotels without food and beverage in clusters with large proportions of luxury and upscale hotels. Similarly, high-end hotels that pursue differentiation strategies experience price erosion when they are in the same geographic location as lower-end hotels. Luxury hotels experienced the greatest price erosion when they operate in locations with large proportions of economy and midscale hotels. The paper concludes with a discussion of the implications of these findings for competitive dynamics and hotel location decisions.
\end{abstract}

\section{Introduction}

Firms in the same industry are highly interdependent as they engage in various actions to improve their relative position and profitability. The series of moves and countermoves among various firms create the competitive dynamics within an industry (Smith, Ferrier \& Ndofor, 2001). Firms likely to prosper are most able to anticipate the actions of others in their location and exploit their resources through the initiation of strategic responses. While many strategies can be deployed to succeed in competitive settings, such as brand affiliation, cost controls, and revenue management, this paper suggests that the composition of hotels in a specific geographic location can also shape the competitive landscape. 
Can firms enhance their relative competitive position simply by co-locating with the right mix of other hotels? In contrast to the traditional view of competitive dynamics, it may be possible for a hotel to reap a price benefit just by locating in a particular cluster of hotels. Detriment may also be experienced by a high-end hotel if it is located close to lower quality hotels. Whether benefit or detriment comes from co-location we argue will depend on the competitive strategies of firms in the cluster. The purpose of this paper is to explore the degree to which a firm can extract a price premium, or suffer price erosion as a result of the competitive strategies of closely proximate firms. With regard to co-location in an industry cluster, also known as agglomeration, the key issue is whether firms can enjoy some of the benefits associated with higher-quality segmented local competitors without making similar investments in product or service differentiation. The opposite effect is also explored. Will firms that rely on a differentiation strategy experience price erosion when they co-locate in a cluster with others in lower segments of the industry. The price benefits or detriments that a firm obtains by locating in a specific cluster of other firms is termed "spillover". Spillover occurs when the benefits from the strategies of one firm spill over to other firms. We examine the nature of these positive and negative "spillover" effects with a sample of 14,995 hotel properties, representing over half of the lodging revenues in the United States.

In the sections to follow the conceptual framework of agglomeration economics and our hypotheses will be developed. The methodology section describes the sample, variables, and the feasible generalized least squares (FGLS) data analysis model used in this comprehensive study of hotel pricing behavior. We conclude the paper with a discussion of the results in the context of competitive positioning and hotel location decisions.

\section{Theoretical Background}

This section begins with a brief introduction to how location and co-location affect hotels' pricing strategies. The theoretical foundations of agglomeration economics and key empirical studies within the lodging industry are then reviewed. The section concludes with an elaboration on how competitive strategy sets the baseline for hotel pricing, including a treatment of the consumer behavior pricing approach.

Location, Co-location and Pricing Strategy

Location selection and pricing decisions are critical for businesses with uncertain demand, high costs of product reconfiguration, geographic dispersion, and segmented competition (Baum \& Haveman, 
1997). Many studies (Porter, 1994; Bennison, Clarke \& Pal, 1995; Pantzalis, 2001) have addressed location as a competitive advantage for firms. The striking and persistent differences in the economic performance of nations, states, and cities demonstrate that location is not an irrelevant factor (Porter, 1994). In the hotel industry, marketers have freely asserted that "location, location and location" are the three most important attributes that a hotel can offer (Bull, 1994). Some studies have suggested that location is among the most important determinants to attract guests to hotels (Mayo, 1974; Cadotte \& Turgeon, 1988; Horak, 1997).

Location has become a major factor that influences strategy, especially for promotion and pricing strategies (Bull, 1994). Among the many forms of segmented pricing strategy, location pricing suggests that firms charge different prices for different locations (Armstrong \& Kotler, 2004). Retail chains use geo-demographic price discrimination strategies to allot different prices to different markets or segments according to their geographic location (Gonzalez-Benito \& Gonzalez- Benito, 2004). Location has also become an important asset for a hotel's pricing decision (Luk, Tam \& Wong, 1995). Based on the idea of location pricing, hotel managers often charge price premiums for their lodging products with good locations.

Generally, the value of location is measured by distance from specific places such as city center, airport, beach or highway (Bull, 1994; Wind, Green, Shifflet \& Scarbrough, 1989; Arbel \& Pizam, 1977). An equally important measurement for the value of location is the amenity or quality of the surrounding area. Among the vicinity factors that may affect the value of a hotel location, the characteristics of other hotels in the same cluster plays a very important role (Baum \& Haveman, 1997; Chung \& Kalnins, 2001; Kalnins \& Chung, 2004; Canina, Enz \& Harrison, 2005). This study focuses on the pricing strategy of hotels in a geographic cluster and investigates the impact of the characteristics of the hotels in the cluster on pricing. We now turn to the agglomeration literature which offers a theoretical framework within which to explore the positive and negative externalities associated with geographic clustering.

\section{The Role of Agglomeration}

Agglomeration describes industry clusters of firms within a particular geographic region (Baum \& Mezias, 1992; Baum \& Haveman, 1997; Chung \& Kalnins, 2001). The analysis of agglomeration originated from Alfred Marshall's (1920) concept of external economies (the advantages that are open to and shared among a collectivity of businesses). The existence of positive externalities has the potential to enhance the performance of agglomerating firms and promotes the geographical agglomeration of economic activity (Shaver \& Flyer, 2000; Phelps, 2004). 
"Agglomeration is counterintuitive from a traditional economic perspective since competitive influences typically are associated with a reduction in performance" (Canina et al., 2005, p. 566). Traditional competitive dynamics indicate that co-locating with firms from the same industry may increase competition for resources and cause damage (i.e. price competition and hence reduced prices) among these closely located firms. For example, Baum and Mezias (1992) found that increased failure rates in the Manhattan hotel industry over the past century were due to localized competitive influences. Alcácer (2004) suggested that competition discouraged firms from co-locating when markets are equally attractive and products are homogeneous.

However, benefits from co-location are also supported in the literature. Several researchers in the field of strategy have observed that highly successful firms from the same industries tend to be located in geographic clusters (Porter, 1998). "Shopping malls house multiple clothing and shoe stores; antique dealers and jewelry dealers are often found in areas colloquially named 'Antique Row' or 'Jewelers Row'”(Fischer \& Harrington, 1996, p. 281). Other examples include competitive clusters in entertainment (Hollywood), computer technology (Silicon Valley), high-tech automobiles (southern Germany), and textiles (the Carolinas in the US).

Marshall (1920) indicated that there are two types of agglomeration gains: those yielding production enhancements and those yielding heightened demand. The three sources that enhance production are: access to specialized labor, access to specialized intermediate inputs, and knowledge spillovers (Marshall, 1920). Jaffe, Trajtenberg and Henderson (1993) suggested that manufacturing firms contribute to and benefit very differently from spillovers based on the resources they themselves possess.

The major benefit of co-location in service enterprises is heightened demand because the consumer can evaluate a variety of offerings within a given area (Fischer \& Harrington, 1996). Consumers are more likely to be attracted to an area with a large selection of competing services (Canina et al., 2005). Restaurants for example often locate right next to each other in a restaurant district, while quick-service restaurants tend to build in very close clusters along major streets. The advice of professionals who help foodservice chains make site selection decisions provides further evidence of the power of agglomeration. One expert when offering advice to Pizza restaurants recommended, "Get as close as you can to a traffic heavy retail hub. Look for fast-food places like McDonald's and Burger King" (Karington, 2007). When firms have functional linkages that benefit from proximity, the existence of agglomerative forces will bring retail firms together if they sell complementary goods (Miller, 1996). 
Under the condition of excessive demand, customers will likely choose another nearby hotel when there is no vacancy at the hotel where they initially intend to stay (Chung \& Kalnins, 2001). When travelers stop along a roadside for the night there are usually an array of hotels next to the highway exit. This co-location enables the customer to easily compare neighboring properties. With the rising popularity of online hotel booking travel search engines (i.e. www.expedia.com) listing all hotels in a specific city district has become a new way in which customers are provided with co- location choices.

Researchers have found that co-location benefits accrue to some firms more than others (Canina et al., 2005; Chung \& Kalnins, 2001). Shaver and Flyer (2000) reported that heterogeneous firms differ in benefits from agglomerating. Firms using differentiation strategies (with better technologies, human capital, training programs, suppliers or distributors) will gain less than those with inferior products or services. The lower-end firms can benefit from the spillover contributed by the differentiated firms without additional investment. Interestingly, previous work has suggested that agglomeration can even harm some firms (Baum \& Mezias, 1992). Depending on the strategies of others in the same geographic cluster, a firm will gain or be harmed competitively.

\section{Agglomeration Studies in the Lodging Industry}

The lodging industry is an especially good context in which to study agglomeration effects because there are many clusters and the characteristics of these clusters can be compared. It also provides a specific context to test the agglomeration effect brought by heightened demand, resource heterogeneity and resource spillovers (Kalnins \& Chung, 2004). In a hotel cluster, the existence of luxury and higher-end hotels increases the attractiveness of an area as a destination. This can be due to their service quality, architectural features, and reputations, to name but a few factors that enhance colocation next to high-end hotels.

A few agglomeration studies have focused on these effects in the hotel industry. By analyzing archival data on 614 transient hotels operating in Manhattan between 1898 and 1990, Baum and Haveman (1997) found that "hoteliers locate new hotels sufficiently close to established hotels that are similar on one product dimension (price) to benefit from agglomeration economies, but different on another product dimension (size), to avoid localized competition and create complementary differences"(p. 304). They concluded that hotels are more likely to co-locate with similarly priced neighboring incumbent hotels to realize agglomeration effects. The study only measures the absolute value of the price distance between entry hotels and incumbent hotels rather than an actual price differences (be it positive or negative). 
Using data from Texas hotels and motels in 1992, Chung and Kalnins (2001) found evidence of heightened demand from agglomeration and the heterogeneity of agglomeration effect. Hotels in markets populated by a higher fraction of chain affiliated and large hotels experienced higher revenues per room. Their study suggests that it's valuable to compare the effects (benefits or detriments) of agglomeration in hotel clusters with different characteristics. In a follow-up study with data from 570 new hotels operating in Texas between 1990 and 1999, Kalnins and Chung (2004) proposed that, "entrants will locate near others possessing resources that can spill over, but will avoid locations where existing firms will exploit spillovers without contributing" (p. 689).

Based on broad US hotel industry data, Canina et al. (2005) showed that higher quality hotel providers within the industry are more likely to be the providers of agglomeration benefits, while those at the other end of the product segment continuum (the lowest quality providers) will capture the greatest benefits. For the lodging industry, the heightened demand from agglomeration effects will either increase a hotel's occupancy rate or increase its average daily rate (Chung \& Kalnins, 2001). What remains unclear is exactly which segments provide benefit or add costs to others in an industry cluster. For example, do economy hotels gain greater price benefit from co-locating close to potential direct competitors like mid-scale hotels without food and beverage one segment level up, or can they extract a higher price premium from proximity to a large proportion of hotels that do not tap into the same customer profile, or are several segment levels above? These questions will be addressed in this paper.

\section{Competitive Strategies and Pricing}

Overall cost leadership and differentiation are two generic competitive strategies used by firms to outperform other firms in the same industry (Porter, 1980). To escape the perils of price wars, many firms differentiate themselves by quality and price so that they can pursue different market segments. D’Aveni (1994) explained how firms differentiate themselves by quality and price: taking the position of234 C. A. Enz et al. moderate quality and moderate price as a starting point, some firms can pursue a low-cost producer position, offering lower-quality products with lower prices; others can become differentiators, offering products with higher perceived quality and charging price premiums.

A straightforward way of showing the competitive positions of lodging firms is adapted from the work of D'Aveni (1994) who maps price and perceived quality. Hotel companies differentiate themselves on both price and quality. A budget brand such as Motel 6 offers limited service and charges a lower price, whereas a luxury hotel chain like Four Seasons chooses to provide higher-quality products and services at a higher price. The low-cost and differentiated hotel providers offer fundamentally different 
things to the customer, but they offer similar value in that the customer gets the level of quality that they are willing to pay.

Network theory argues that firms are not free to choose any competitive action. Instead, they must make moves and countermoves within the confines of their geographic cluster (Burt, 1992; Smith et al., 2001). In short, the competitive landscape or composition of players in a location constrains some actions and may enable others. The composition of a market in terms of the product or service segments would suggest that firms in clusters with a large proportion of highly differentiated hotel operators would experience pricing opportunities that firms in clusters with predominately low-cost providers could not use. Differentiation spillover is when a firm enjoys price benefits from the high levels of investment in differentiation made by other hotels in the same location without investing at the same levels (Canina et al., 2005).

The consumer behavior pricing approach also suggests that when firms make price decisions in a marketplace with diverse competitors, they should take into account consumers' choices over competitors' products and prices (Matanovich, Lilien \& Rangaswamy, 1999; Danziger, Israeli \& Bekerman, 2004; Steed \& Gu, 2005). For luxury hotels to maintain their status when competition is strong, Catrett and Lynn (1999) suggest that "discounting may undermine the scarcity and social desirability of a product or service" (p. 36). They recommend that hotel managers "beware of association with non-status brands" because "a status product can be tarnished by affiliation with a nonstatus offering" (Catrett \& Lynn, 1999, p. 39).

While there are many ways to conceptualize the composition of competitive players, within the lodging industry fairly well structured and carefully defined segments exist based on the extent to which hotels are differentiated on quality and services offered (Mazzeo, 2002). The classifications are an indication of the "credible commitment" made by firms to a particular level of service quality (Ingram, 1996). In this study we will rely on the widely-used classifications in the industry as indicators of the degree to which a group of firms are pursuing a differentiation or low-cost provider strategy. These classifications include luxury, upscale, midscale with food and beverage services, midscale without food and beverage services, and economy hotels.

\section{Hypotheses}

Who benefits from the strategic choices of closely proximate firms? Many studies have concluded that firms with the weakest resources (i.e. smaller or low-end hotels) will gain from the agglomeration effect (Shaver \& Flyer, 2000; Chung \& Kalnins, 2001; Canina et al., 2005). The hypotheses 
linking the agglomeration effects to hotel pricing for firms pursuing different strategies is summarized in Figure 1. In this study, we propose that firms deploying low-cost provider strategies will be the recipients of price premiums when they are in a network of hotels with several segments higher or highly differentiated products and services. In Figure 2 we show an industry map in which the proportion of luxury hotels is greater as illustrated by a larger circle to represent the number of firms within this segment. While hotels in different segments offer products with different qualities and charge different prices, when a low-end hotel is in a primarily higher-end market, it may obtain the price spillover benefit, as shown by the line that moves all segments into a higher price position. This is a desirable competitive position for the low-end hotel since it does not have to compete on product quality but still obtains a price premium.

When an economy hotel co-locates with a large proportion of highly differentiated hotels (upscale and luxury), it can enjoy a price premium contributed by those high quality hotels, and may even be perceived to offer higher quality without necessarily doing so. Hence we offer the following hypothesis:

H1: Firms deploying low-cost provider strategies (economy and midscale w/o F\&B hotels) will be the recipients of price premiums when they are in a hotel cluster with a large proportion of highly differentiated hotels (luxury and/or upscale hotels).

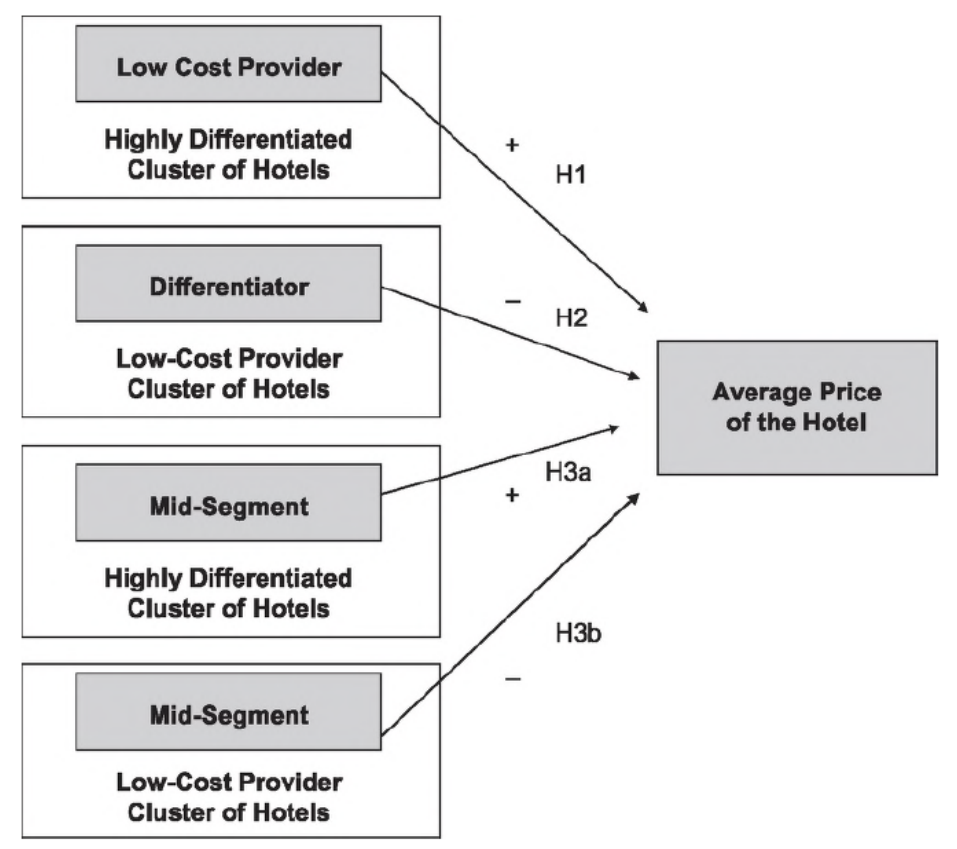

Figure 1. Hotel strategy, competitive cluster and pricing hypotheses. 


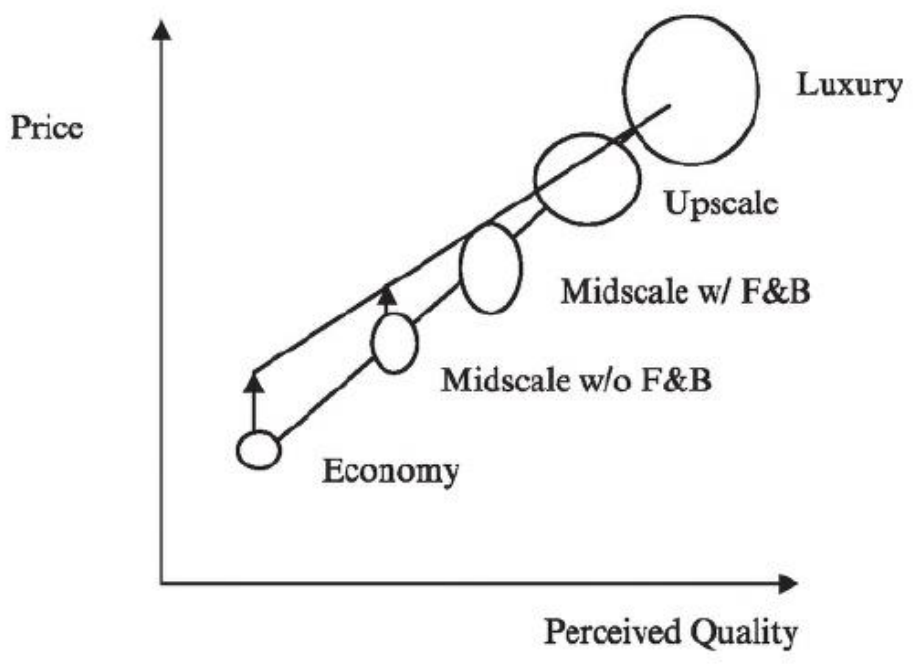

Figure 2. Price premiums from agglomeration effect.

Note: The sizes of the circles are proportional to the ratio of each type of hotels in a hotel cluster.

There are many possible reasons that highly differentiated hotels within the same cluster are likely to be the providers of price premiums while the lowest quality firms will capture the benefits. First, hotels separated by several product quality segments are not direct competitors. The heterogeneity of market segments that differentiated firms (high-end hotels) and low-cost provider (low-end hotels) are targeting helps to avoid direct competition between them. This is important because the heterogeneity that facilitates agglomeration benefits does not evoke between segment competition. For example, a customer who might stay at a Westin Hotel will not trade down to a Comfort Inn, or visa versa. Another reason why higher-end hotels provide benefit is due to the costs of differentiation and the associated high prices that must be obtained in order to recoup those costs. Lower- end hotels can obtain price premiums from these other hotels' investments when for example their customers use the public or meeting facilities of higher-end hotels while staying in closely proximate low-cost operations. It is also possible that co- location with higher-end hotels can improve the image of the lower-end hotels. Therefore, customers would pay a price premium for the higher perceived quality of the low-cost providers.

A variety of other factors may contribute to price decisions including brand affiliation (Ingram, 1996; Thrane, 2007), regional location (e.g. northern vs. mountain), and setting within a market (e.g. urban vs. highway) (Bull, 1994; Wind et al., 1989; Chung \& Kalnins, 2001). In addition, characteristics of the local market in terms of population density, land area, and number of service, retail, and manufacturing establishments can shape demand. Finally, other aspects of the market such as the 
overall heterogeneity or variety of different segmented hotels in a market and their size can shape pricing behavior (Chung \& Kalnins, 2001). To assure that these variables are not unduly altering the impact of proximity to other firms, we will control for a variety of these factors in the current study. At the individual hotel level, number of rooms, chain affiliation, and setting (urban, airport, etc.) are all factors that could elicit price variations. In addition various locations within a country are able to extract higher prices, so regional location is also controlled. Finally, the proportion of larger size hotels in the cluster and the heterogeneity of strategies pursued by all firms in the cluster are also held constant.

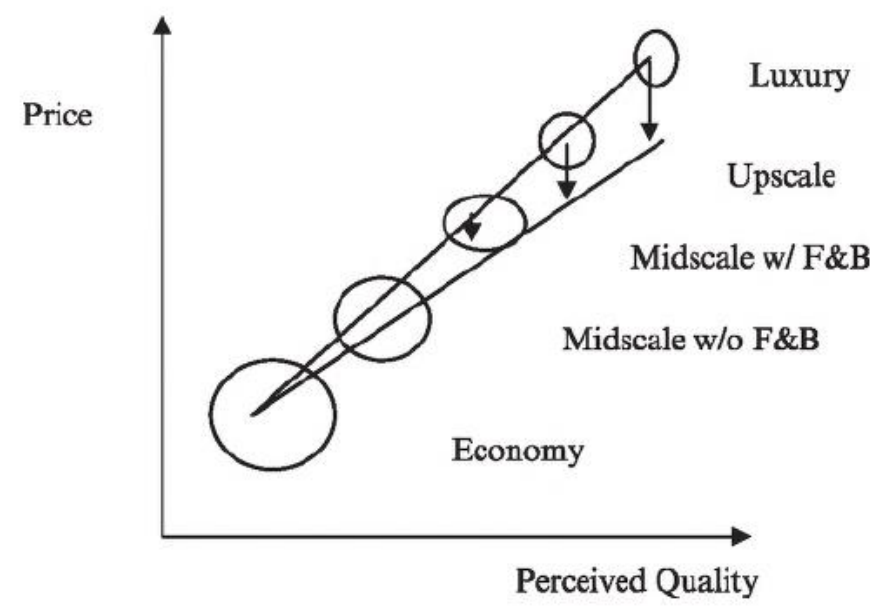

Figure 3. Price erosion from agglomeration effect.

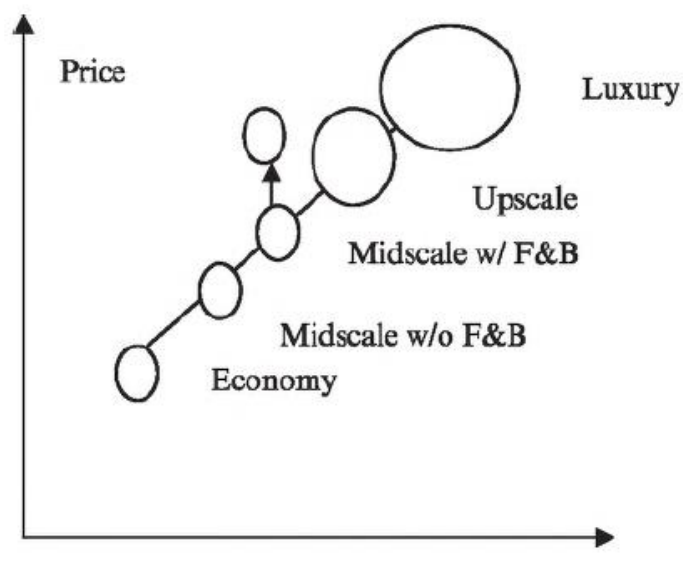

Perceived Quality A Price Benefit

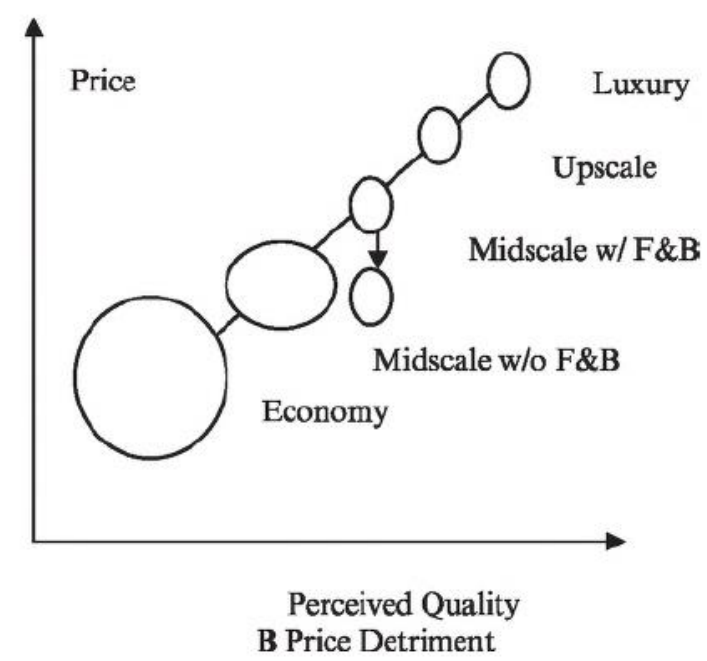

Figure 4. Price premium and price erosion for Midscale Hotels w/ F\&B.

While the first hypothesis explored who benefits from co-location with others pursuing different strategies, it is also likely that some firms may give benefit, but receive harm. The focus of the second 
hypothesis is on who is harmed in a geographic cluster. Previous studies suggested that firms with the highest resources will gain little or even suffer from co-location with low-resources firms (Shaver \& Flyer, 2000; Canina et al., 2005). Consistent with those studies, we expect price erosion to occur for those highly differentiated firms that are located in clusters with far lower-quality firms. Figure 3 shows a change in the location of luxury and upscale hotels when they are in close proximity to lower-end hotels in predominately lower quality clusters. The price position for these hotels is lowered as a result of co- location next to lower-quality firms.

Competitors pursuing a low-cost strategy do not contribute as much to the attractiveness of a location because they do not offer the range of products and services that co-located firms can benefit from. If many low-cost providers are found in the same cluster, agglomeration effects will be negative for those firms pursuing differentiation strategies several segments above the low-end providers as the following hypothesis suggests:

H2: Firms deploying differentiating strategies (luxury and/or upscale hotels) will endure price erosion when they are co-locating with firms pursuing low- cost provider strategies (economy and midscale hotels without food and beverage services).

Hotels in the middle (midscale with food and beverage) will either benefit from price premiums or be harmed by price erosion depending on the proportions and types of other hotels in the same cluster. Co-locating with firms offering highly differentiated products and services (luxury and/or upscale hotels) can provide price premiums to mid-scale hotels (Figure 4-A). However, if there are a large proportion of low-end hotels (economy and/or midscale without F\&B) around them, tend to suffer from price erosion caused by co-location with low-resource firms. Figure 4 illustrates the possibility for both price benefits and price erosion for these mid-market properties depending on the composition of the cluster in higher or lower segments of the industry. In a hotel cluster, in which there are similar proportions of higher-end and lower-end hotels around the middle market hotels, the positive and negative agglomeration effects may neutralize each other. Therefore, the agglomeration effect may not be observable.

H3a: Firms in the middle (midscale w/ F\&B hotels) will be the recipients of price premiums when they are in a hotel cluster with a large proportion of highly differentiated hotels (luxury and/or upscale hotels).

$H 3 b$ : Firms in the middle (midscale w/ F\&B hotels) will endure price erosion when they are co-locating with firms pursuing low-cost provider strategies (economy and midscale w/o F\&B hotels). 
The extent of the price benefit or erosion will depend on the make-up of the cluster. For lowcost providers, the more differentiated the other firms' products and services the greater the price benefit. Lower-segmented firms (economy hotels) will reap price premiums when they are located in a cluster with a large proportion of highly-segmented firms (upscale and luxury hotels). The lowestsegmented firms gain greater price premiums with the increasing of the proportion of firms pursuing a strategy that is as distant as possible from their own. The largest benefit will be derived from location in a geographic cluster with hotels several segments above the focal hotel, such as an economy hotel in a cluster with a large proportion of luxury hotels.

In contrast, the more the low-cost providers, the greater the price erosion will be. The luxury firms will experience the greatest price erosion when they are located in a cluster with a large proportion of the lowest price providers. High-segmented firms (luxury hotels) will endure price erosion when they co-locate in a cluster with a large proportion of lowest-segmented firms (economy hotels). The highest-segmented firms face greater price erosion with the increasing of the proportion of firms pursuing a strategy that is as distant as possible from their own.

To summarize, the greatest price impact of co-location will be experienced in those clusters in which the largest proportion of other firms are in a segment that is most distant from the segment of a given hotel. The following hypotheses are offered to explore this issue:

H4a: Prices premiums will be greater for low-cost providers when there are a large proportion of firms with greater segment distance in the same geographic cluster.

H4b: Prices erosion will be greater for highly-differentiated firms when there are a large proportion of firms with greater segment distance in the same geographic cluster.

\section{Method}

\section{Data Source}

The key variables in this study were obtained from Smith Travel Research (STR), an independent research organization that tracks lodging performance for all major North American hotels. STR has one of the most comprehensive data sources available on the lodging industry, and the data was obtained through strict and exclusive confidentiality arrangements. The data captures hotels across the entire United States, including over $98 \%$ of the chain hotel inventory within the United States. Independent hotels are also included in this study and constitute a total of 1,162 hotels in the sample of almost 15,000 . 


\section{Measured Variables}

Strategy-Based Agglomeration: Agglomeration, the key independent variables in this study capture the composition of hotels clusters according to their strategic orientation. Hotels can be in clusters with either higher or lower quality hotels. The agglomeration variables in this study measure the proportion of hotels in given cluster segments above or below the segment of the focal hotel. A luxury hotel for example will only be in clusters with hotels in lower segments, and four agglomeration variables are possible for these high end hotels. A luxury hotel could be in a cluster with hotels in upscale, midscale with and without food and beverage, and economy hotels (a total of four different segments). In this study we measure the proportion of hotels in a given hotel's local cluster by segments above or below.

A total of eight strategy-based agglomeration or co-location measures were created. Each of these measures constitutes the proportion of lodging properties in a given cluster that are pursuing a quality segment above or below the focal hotel's segment. For example, if the hotel was in the midscale market with food and beverage, the proportion of hotels pursuing one segment above would be upscale hotels, and two segments below would be economy hotels. Agglomeration effects were measured at the tract level. Tracts are defined by the data provider, Smith Travel Research, as a subset of a Metropolitan Statistical Area. The advantage of using the tract as the geographic cluster in this study is that it is the smallest location grouping unit for studying agglomeration, for which data can be obtained. Hence, lodging properties will be examined with their tracts as the geographic location for comparison and agglomeration affects.

Pricing Variable: The most common measure of hotel room price is the average daily rate (Enz, Canina \& Walsh, 2001). The key dependent variable in this study was average daily rate (ADR). Since a variety of different prices are offered to customers, the average daily rate gives the average, taking into consideration the variation that may be due to revenue management activities and business mix. Average daily rate was calculated using monthly data aggregated to the annual level in order to eliminate seasonal fluctuations within clusters that could reduce our ability to discern true pricing effects.

Control Variables: Many factors other than co-location impact the pricing of lodging firms.

Hotel Size: A size-based agglomeration variable was added to the models to take into consideration the unique contribution of hotel size. It was measuring as the proportion of properties in a cluster that are larger in size than the focal firm, based on the number of rooms. 
Strategic and Size Dispersion: We also added a control for within-tract product/ quality heterogeneity (strategic dispersion). The segment distance was measured by assigning a number 1 to 5 to the five types of hotels (economy=l, midscale $w / o F \& B=2$, midscale $w / F \& B=3$, upscale $=4$ and luxury=5). The segment distance is measured by the absolute value of the differences of those typology numbers. For example, the segment distance between a midscale hotel w/o F\&B and a luxury hotel is $|2-5|=3$. Creating a Herfindahl-type index, we measured the level of concentration vs. dispersion of competitive strategies in a given cluster. To do so, we tallied the number of hotels in each product/quality segment, and then divided each tally by the total number of hotels in the cluster. We squared each of these proportions and then summed them. High values suggest that the cluster is concentrated with respect to strategic type; low values suggest that the cluster is strategically dispersed. We also controlled for size dispersion with the coefficient of variation, calculated as the standard deviation of within-cluster size divided by the mean.

Hotel Characteristics and Location: Four characteristics of the hotel were provided: the size by number of rooms, whether it is brand affiliated, the location type, and the geographic region of the hotel. Chain affiliation was controlled using a dummy variable (Chain Affiliation) to represent hotels as either brand affiliated $(=1)$ or independent $(=0)$. With regard to location of the hotel, urban and resort locations are expected to have higher prices on average than suburban, airport and highway locations. To control for the differences in price across locations dummy variables were created for each of the setting categories, with 1 signifying that a hotel belongs to the category and 0 if it does not. We also expect that hotels in highly populated regions with expensive real-estate will also have higher prices than hotels in more sparsely populated regions. Hence, we controlled for location using nine dummy variables. Population, the land area in square miles, and the sum of the number of retail, service and manufacturing establishments in the cluster were additional demand-related control variables included in the models for the metropolitan area to which the hotel belongs.

\section{Data Analysis Approach}

In a normal ordinary least-squares (OLS) or multiple linear regression model parameters and residual covariance matrices are calculated assuming an independent underlying distribution. In circumstances in which there is dependence across observations within a cluster, as is the case in the data used in this study, use of the simple multiple regression model can result in erroneous conclusions (Greene, 2000). Feasible generalized least squares (FGLS) is a regression technique that accommodates misspecified models or models with nonsperical errors. The procedure is to do a least-squares 
regression, then do a covariance-weighted least-squares regression with the residual covariance from the first regression model.

A feasible generalized least squares (FGLS) procedure was used to test our hypotheses because of the potential for positive spatial correlation when relying on an ordinary least squares (OLS) approach (Azzalini, 1994; Hall \& Severini, 1998; Rowell \& Walters, 1976). Positive spatial correlation is the tendency of observations closer together to be more alike than observations farther apart. The data necessitate a FGLS procedure because the set of observations tend to be intercorrelated. This correlation must be taken into account to draw valid inferences. In our sample, observations within the same market are assumed to be correlated resulting in a covariance matrix of the errors where the offdiagonal terms within a market are nonzero. In addition, we did not impose homoskedasticity across markets. When the covariance matrix of the errors is unknown, it is necessary to use the feasible generalized least squares (FGLS) model where the covariance matrix of the errors is replaced with an estimate of the matrix. The results of FGLS analysis can be interpreted similarly to OLS regression.

\section{Results}

Five feasible generalized least squares regression models were estimated, one for each of the five segments in the lodging industry, as shown in Table 1, Columns 1 through 5. The impact of colocation on the room price of the focal hotel is shown by the magnitude and statistical significance of the strategy -based agglomeration variables. As discussed previously the values of these variables measure the proportion of hotels in a given cluster above or below the segment of the focal hotel. A luxury hotel for example (Column 1) will only be in clusters with hotels in lower segments, and four strategy-based agglomeration variables are possible for these high end hotels: upscale, one segment down; midscale with food and beverage, two segments down; midscale without food and beverage, three segments down; and, economy, four segments down. Upscale hotels (Column 2) will be in clusters with luxury hotels, one segment above, and hotels that are one through three segments below (midscale with food and beverage through economy).

In hypothesis 1, we predicted that low-cost hotels will be the recipients of price premiums through co-locating with hotels that pursue higher levels of differentiation. Strong support was found for the first hypothesis that price premiums exist for low-cost providers such as economy and midscale without food and beverage hotels that co-locate in the same geographic cluster with large proportions of the highly segmented firms in the industry such as luxury and upscale hotels. The results for the economy segment are shown in Column 5 and those for the midscale without food and beverage in 
Column 4. Economy hotels gained significant price premiums from co-location with luxury (four segments up). The coefficient of 0.19 is positive and statistically significantly different from zero at the 0.001 significance level, $(p<0.001)$. This implies that as the proportion of luxury hotels increases in the local market, the ADR of economy hotels also increases. The proportion of upscale hotels (three segments up) also has a positive impact on the ADR of economy hotels (i.e. coefficient of 0.14 significant at $p<0.01$ ). The insignificant coefficients on the proportion of midscale with food and beverage (two segments up) and midscale without food and beverage (one segment up) imply that economy hotels did not experience pricing benefits when they were in clusters with large proportions of more direct competitor hotels in the midscale segments. Further support for hypothesis 1 is evidenced by the results for the midscale hotels without food and beverage, as shown in Column 4. Since the coefficients are positive and statistically significant this implies that midscale hotels without food and beverage gained price premiums by locating in clusters with upscale hotels (two segments up, coefficient of $0.24, p<$ 0.001 ) and luxury hotels (three segments up, coefficient of $0.35, p<0.001$ ). The magnitude of the benefit was greatest due to the luxury hotels that were in their clusters (three segments up, coefficient of 0.35, $p<0.001)$. The ADR of midscale with food and beverage also benefited from their proximity to upscale hotels (one segment up, coefficient of $0.2, p<0.01$ ) as well as with luxury hotels (two segments up, coefficient of $0.29, p<0.001$ ). Finally, upscale hotels did not gain co-location benefit from proximity to luxury hotels as evidenced by the insignificant coefficient of 0.04 . Overall these results show that price premiums can be obtained from co-location with hotels that are in higher segments. It also appears that midscale hotels are the greatest beneficiaries of price premiums when in markets with substantial populations of luxury and upscale hotels. This is evidenced by the relative magnitude of the coefficients. For example, the coefficient of three segments up (luxury hotels) for midscale without food and beverage is 0.35 while the coefficient of three segments up (upscale hotels) for economy is 0.14 and for four segments up (luxury) the coefficient is 0.19 .

Support was found for Hypothesis 2 that predicted firms would suffer price penalties from colocation with hotels that were using low-cost based strategies. Luxury hotels experienced the greatest harm to their pricing by co-locating with all but upscale hotels (coefficient of -0.07 for one segment down, upscale but not significant). Each of the coefficients on the other strategy-based agglomeration variables for the luxury segment were negative and statistically significant: -0.58 for two segments down (midscale with food and beverage); -0.94 for three segments down (midscale without food and beverage); and -0.82 for four segments down (economy). Upscale hotels experienced negative effects on pricing in markets with large proportions of midscale hotels (one and two segments down), but these 
results were not significant. The prices set by upscale (coefficient of $-0.53 p<0.001$ ) and midscale with food and beverage hotels (coefficient of $-0.21 \mathrm{p}<0.01$ ) were harmed by the presence of large proportions of economy hotels, three and two segments down, respectively. The empirical results supported the hypotheses that midscale hotels with food and beverage could be recipients of either price premiums or price erosion, as stated in hypotheses $3 \mathrm{a}$ and $3 \mathrm{~b}$. The existence of a large proportion of highly differentiated hotels in the same cluster will increase the prices of midscale hotels with food and beverage; nevertheless, the prices of these midscale hotels will be eroded by co-locating with a large number of low- end hotels. For example, as shown in Column 3, midscale with food and beverage hotels, receive price benefits of 0.29 due to co-locating with hotels that are two segments higher (luxury) while their price is reduced by -0.21 through co-locating with hotels that are two segments down, economy hotels.

Finally, hypotheses $4 \mathrm{a}$ and $4 \mathrm{~b}$ that the greatest price impact of co-location will be experienced in those clusters in which the other firms are in a segment that is most distant from the segment of a given hotel was supported, as the size of the coefficients in Table 1 suggest. As the proportion of hotels in a geographic cluster came from segments that more directly competed with a hotel, the price premium and also the price erosion were diminished. To get the maximum price premium, hotels needed to be in locations with the most competitively distant or most differentiated firms in the industry, several segments away from their own competitive set. Greater price erosion came from co-location in markets with firms that were providing substantially lower-segmented products and prices. The implications that emerge from these findings will be discussed next.

The significance of the various control variables varied by hotel segment, although strong effects were found for setting and region. Prices were also shaped by chain affiliation, with positive effects for lower-end hotels and negative effects for higher- end hotels. These results suggest that brand affiliation enhances price for hotels that pursue low-cost provider strategies, but harm price for highly differentiated hotels. Midscale hotels with food and beverage may be stuck in the middle, without significant gain or loss of price due to branding. 
Table 1. Regression models of the impact of strategic agglomeration on pricing for hotels in various quality segments.

\begin{tabular}{|c|c|c|c|c|c|}
\hline Variables & $\begin{array}{l}\text { Luxury } \\
\text { Hotels }\end{array}$ & $\begin{array}{l}\text { Upscale } \\
\text { Hotels }\end{array}$ & $\begin{array}{c}\text { Midscale } \\
\text { (with F\&B) } \\
\text { Hotels }\end{array}$ & $\begin{array}{c}\text { Midscale } \\
\text { (no F\&B) } \\
\text { Hotels }\end{array}$ & $\begin{array}{l}\text { Economy } \\
\text { Hotels }\end{array}$ \\
\hline & (1) & (2) & (3) & (4) & (5) \\
\hline $\begin{array}{l}\text { Intercept } \\
\text { Strategy-Based }\end{array}$ & $184.39^{* * *}$ & $137.22^{* * *}$ & $84.33^{* * * *}$ & $46.13^{* * *}$ & $33.91^{* * *}$ \\
\hline Agglomeration & & & & & \\
\hline $\begin{array}{l}\text { Agglomeration of } \\
\text { four segments down }\end{array}$ & $-0.82^{* * *}$ & & & & \\
\hline $\begin{array}{l}\text { Agglomeration with } \\
\text { three segments down }\end{array}$ & $-0.94^{* * *}$ & $-0.53^{* * *}$ & & & \\
\hline $\begin{array}{l}\text { Agglomeration with } \\
\text { two segments down }\end{array}$ & $-0.58^{* *}$ & -0.28 & $-0.21^{* *}$ & & \\
\hline $\begin{array}{l}\text { Agglomeration with } \\
\text { one segment down }\end{array}$ & -0.07 & -0.26 & $-0.16^{*}$ & 0.04 & \\
\hline $\begin{array}{l}\text { Agglomeration with } \\
\text { one segment up }\end{array}$ & & 0.04 & $0.2^{* *}$ & $0.14^{* *}$ & 0.01 \\
\hline $\begin{array}{l}\text { Agglomeration with } \\
\text { two segments up }\end{array}$ & & & $0.29 * * *$ & $0.24^{* * *}$ & 0.08 \\
\hline $\begin{array}{l}\text { Agglomeration with } \\
\text { three segments up }\end{array}$ & & & & $0.35^{* * *}$ & $0.14^{* *}$ \\
\hline $\begin{array}{l}\text { Agglomeration with } \\
\text { four segments up }\end{array}$ & & & & & $0.19^{* * *}$ \\
\hline \multicolumn{6}{|l|}{ Cluster Controls } \\
\hline Size agglomeration & $0.18^{*}$ & $0.09^{* * *}$ & $-0.04^{*}$ & -0.02 & $0.11^{* * *}$ \\
\hline Strategy dispersion & 5.29 & $1.89^{*}$ & $1.35^{*}$ & 0.52 & $0.54^{*}$ \\
\hline Size dispersion & 5.94 & -3.83 & -7.09 & -2.75 & 3.24 \\
\hline \multicolumn{6}{|l|}{ Hotel Controls } \\
\hline Number of rooms & -0.01 & $0.01^{*}$ & $0.02^{*}$ & -0.01 & 0.02 \\
\hline Chain affiliation & -5.30 & $-5.83^{* *}$ & 1.30 & $18.13^{* * *}$ & $9.54^{* * *}$ \\
\hline Urban setting & $-35.75^{* * *}$ & $-11.98^{* *}$ & $-11.05^{* * *}$ & $-5.23^{*}$ & $-7.74^{*}$ \\
\hline Suburban setting & $-41.35^{* * *}$ & $-15.78 * * *$ & $-14.44^{* * *}$ & $-7.24^{* * *}$ & $-9.00^{* *}$ \\
\hline Airport setting & $-45.04^{* * *}$ & $-14.05^{* * *}$ & $-16.82^{* * *}$ & $-7.88^{* * *}$ & $-10.37^{* * *}$ \\
\hline \multicolumn{6}{|l|}{ Location Controls } \\
\hline Midatlantic & $26.39^{* *}$ & 3.20 & $7.75^{*}$ & $8.77^{* *}$ & 5.40 \\
\hline Southatlantic & -2.90 & $-15.79 *$ & $-7.00^{*}$ & -2.36 & -5.23 \\
\hline Northern & -4.85 & $-16.73^{*}$ & -2.43 & 0.42 & -3.82 \\
\hline Southern & -9.82 & $-22.32^{* *}$ & $-8.08^{*}$ & -3.50 & $-6.00^{*}$ \\
\hline West North Central & -10.50 & $-22.21^{* * *}$ & -6.13 & -3.74 & -4.85 \\
\hline West South Central & -0.68 & $-19.43^{* *}$ & -5.56 & -3.80 & $-7.22^{*}$ \\
\hline Mountain & -0.16 & $-17.22^{*}$ & $-8.32^{*}$ & $-5.72 *$ & $-6.11 *$ \\
\hline Pacific & 15.15 & -8.76 & 1.37 & 3.05 & 1.85 \\
\hline Population & $-7.76 \mathrm{E}-06^{*}$ & $-1.62 \mathrm{E}-06$ & $-5.94 \mathrm{E}-06^{* *}$ & $-5.15 \mathrm{E}-06^{* * *}$ & $-5.57 \mathrm{E}-06^{* * *}$ \\
\hline Land & -0.00 & -0.00 & -0.00 & -0.00 & $-0.00^{*}$ \\
\hline Establishments & $0.00^{* *}$ & 0.00 & 0.00 & $0.00^{* * *}$ & $0.00^{* * *}$ \\
\hline
\end{tabular}

${ }^{* * *} p<0.001 ;{ }^{* *} p<0.01 ; * p<0.05$.

\section{Discussion}

The models provide strong support for the idea that lower-quality competitors can gain benefits from co-locating in a market with higher-quality competitors. The results show that lower-cost hotels 
such as economy and midscale hotels gain price premiums from co-locating in markets with a larger proportion of firms pursuing a higher-quality differentiation strategy such as luxury and upscale hotels. Differentiation spillover would suggest that the economy competitors enjoy price benefits from the upscale or luxury hotels without making similar financial investments. In addition, the results show that highly differentiated hotels such as luxury hotels do not benefit from co- location with low-cost providers. In fact, highly differentiated competitors suffer from negative spillover if a high proportion of the other firms in their clusters are in the economy or the midscale segments. It is important to observe that these effects were consistent and found across all strategy segments.

These findings have implications for the effectiveness of pursing a differentiation versus a cost leadership strategy. For a differentiation strategy to succeed, the additional revenue generated as a result of creating differentiating features should exceed the additional costs of creating those features (Porter, 1985, p. 153). However, differentiation attempts can be problematic if the source of differentiation provides benefits to competing firms without requiring them to make the associated investments. If co-location reduces the ability of high-end firms to distinguish themselves on factors other than location, then it is possible or even probable that lower-end firms can enjoy some of the demand advantages created by the higher-end firms. While all lower-end firms reap agglomeration benefits from co-location with higher-end firms, we find evidence to suggest that strategic segments that are co-located with higher-quality products and services may be the greatest beneficiaries from differentiation spillovers. Based on coefficient values, midscale hotels appear to reap the greatest positive agglomeration effects followed in descending order from higher to lower quality segments.

In a low-tech service industry such as lodging, restaurants or retails stores, higher- end competitors may have difficulty preventing lower-end competitors from entering the same market because of insufficient entry barriers. They may also find that they provide the greatest spillover benefits to firms that are most likely to attract their customers. Our central arguments follow the reasoning that service firms agglomerate, in part, because of the expectation of increased demand. Since our dependent variable is based on demand effects, our results are consistent with this reasoning.

Size was used as a control variable; however, it is interesting to note that we observed the economies of size-based agglomeration for three of the five segment tests. For the most highlydifferentiated firms (luxury and upscale), performance was higher when they operated in clusters of larger sized firms. A similar effect was found for firms pursuing the lowest-cost orientation. These results both confirm and extend past findings. Chung and Kalnins (2001) found that size-based agglomeration influenced performance for firms in rural areas, which would typically be lower-end properties. We 
discovered a similar size-based agglomeration effect but for both highly differentiated firms and lowcost firms.

The results have important implications for our understanding of the competitive dynamics of the industry. They suggest that to avoid price erosion, the owners and managers of luxury hotels would be well advised to not locate in close proximity to any other type of hotel since co-location reduces the ability of high-end firms to distinguish themselves. The other implication of these findings is that firms benefit when they are pursuing strategies that are very different from others in the cluster. Economy hotels get the best price premiums from being in markets with upscale and luxury hotels. This finding is consistent with previous research that would advise firms to break away from the industry to gain competitive advantage (Baumol, Panzar, \& Willig, 1982; Hamel, 1998; Young, Smith \& Grimm, 1996). Low-cost providers should seek clusters that are heavily populated with hotels from extremely different segments.

These results have managerial as well as statistical significance, especially considering that we controlled for so many other factors that influence price. As noted, we would advise luxury hotels to locate outside of hotel clusters, while the economy hotel developer could obtain a disproportionate price premium if locating in the shadows of luxury and upscale hotels. In the end, luxury hotels bear a disproportionate cost associated with differentiating their products or services, while economy and midscale firms can use co-location to share in the benefits from such differentiation. For firms with multiple-brands, the corporation should be very aggressive in assuring that its own lower-end brands, versus its competitors are the recipients of its higher-end hotel spillover benefits.

The practical implications of this study are that low-end competitors gain a benefit from locating near a high proportion of differentiated hotels (positive spillover), while high-end hotels lose value from locating near lower-end competitors (negative spillover). With regard to positive spillover, consider a 144 room midscale firm without food and beverage service that is located in a cluster with $20 \%$ of the luxury hotels. Compare this to a midscale firm (also without food and beverage) that shares a cluster with 60 percent of hotels in the luxury segment. The difference of 40 percentage points (60\% minus $20 \%$ ) can be multiplied by the coefficient of 0.35 (see Table 1, column 4) and then by the average hotel size of 144 rooms, and finally multiply this result by 365 days per year to determine the incremental potential benefit of co-locating with luxury hotels to the firm in the high-quality cluster (60\% luxury) relative to the hotel in the lower quality cluster (20\% luxury), in this case, about $\$ 730,000$. This benefit may increase further dues to differences in the percentage of upscale and midscale with food and beverage properties across the two locations. This estimate is particularly informative, considering that 
we controlled for so many other factors that influence demand. We must note that as differences across clusters are increased or reduced, these numbers will vary and that the coefficient varies from segment to segment, with the strongest effects in the midscale without food and beverage and the lowest in the economy classification. Basically, the results suggest that for higher performance, hotels should try to locate near luxury properties and away from economy hotels.

\section{Limitations and Conclusions}

The finds of this study apply most directly to hotels and other service firms where location is an especially critical variable to success. For many such businesses (e.g. restaurants) co-location is common and local competition is fierce. Our central arguments follow the reasoning that service firms agglomerate, in part, because of the expectation of increased demand from operating in clusters. Price benefits come from two sources. One source of benefit is from co-location with higher segmented hotels. The second source of benefit is from operating a hotel in a lower segment that is more distant from the segment of other hotels in the cluster. While this study included a variety of demand-related control variables, it may not have eliminated the possibility that high hotel density in an area is driven by factors such as tourism attractions or events other than existing hotel clusters. As a result, this area of research would benefit from the inclusion of local tourism attractions and other demand generators as additional controls.

The cross-sectional nature of the data used in this study prohibits us from examining or exploring market "order-of-entry" and identifying the process of cluster formation. A longitudinal study that explores the impact on entry of the cluster profile of existing hotels is a fruitful area for further research. Additional research is needed on the formation and evolution of hotel clusters overtime. Do higher-end hotels enter early and others co-locate to reap the benefit. If so, does this reduce the benefit for the higher-end hotels over time. Early entrants to any business often bear a disproportionate development expense. Locating in a new market can be expensive due to the costs associated with training a local workforce, obtaining necessary community support and other factors such as building permits, and building consumer awareness through promotion and advertising. Our results might suggest that a firm that is more interested in keeping costs low can enter the market cluster later with relatively lower expenses and still reap the advantages created by early entrants. However, we do not test this notion. A longitudinal test of this idea would be appropriate (i.e. Kalnins and Chung, 2004).

In addition, a possible bias could exist due to endogeneity between the location decisions hotel companies were making and their cluster-based performance (Shaver, 1998). However, we do not 
believe that the problem Shaver (1998) identified is likely to be serious in our study. In his conclusion, he states, "Second, to the extent that mistakes are common, the factors that make one strategy more attractive than another are not well understood by decision makers, or all determinants of performance can be identified and measured, self-selection will not affect the estimates of strategy performance" (p. 584). We believe that factors associated with selecting a particular cluster are not well understood by decision makers, especially the primary factor we are examining in this study (influence of the proportion of competitors pursuing a higher level of differentiation). Part of our belief stems from the counterintuitive nature of what we are saying. It is somewhat counterintuitive to think that rates can increase by clustering close to competitor firms. Also, we have included a large set of control variables that represent other location-related factors that influence performance. This should help mitigate possible bias.

In conclusion, this study found pricing benefits and detriments for hotels that locate in various types of competitive clusters. Hotels that locate in close proximity to higher segmented hotels (e.g. economy hotels with upscale and luxury hotels) benefit without making similar product and service investments themselves. Alternatively, co-locating with a high percentage of hotels in lower product segments (e.g. luxury hotels with midscale and economy hotels) erodes the prices of higher segmented properties. These effects are magnified by the degree of between segment differences in the cluster. Luxury hotels did not experience significant price erosion in clusters of upscale hotels, and upscale hotels did not suffer in markets with midscale hotels, reinforcing the distinction between closely competitive and distantly different segment benefits and detriments. Finally, the study revealed that the midmarket hotels can both reap benefit in clusters that are composed of higher segmented firms, and detriment in clusters with lower-end firms. This study by exploring agglomeration in multiple industry segments has provided a major contribution of refining our general understanding of agglomeration dynamics.

\section{Acknowledgments}

The authors gratefully acknowledge the assistance of Smith Travel Research and the Center for Hospitality Research at Cornell University in providing access to the comprehensive lodging performance database used in this study. 


\section{References}

Alcácer, J. (2004) Location choice across the value chain: How activity and capability influence agglomeration and competition effects. Academy of Management Proceedings, J1-J6.

Armstrong, G. \& Kotler, P. (2004) Marketing: An Introduction (Upper Saddle River, NJ: Pearson/Prentice Hall).

Arbel, A. \& Pizam, A. (1977) Some determinants of hotel location: The tourists' inclinations, Journal of Travel Research, 15(3), pp. 18-22.

Azzalini, A. (1994) Logistic regression for autocorrelated data with application to repeated measures. Biometrika, 81, pp. 767-775.

Baum, J. \& Mezias, S. (1992) Localized competition and organizational failure in the Manhattan hotel industry, 1898-1990, Administrative Science Quarterly, 37, pp. 580-604.

Baum, J. \& Haveman, H. (1997) Love thy neighbor? Differentiation and agglomeration in the Manhattan hotel industry, 1898-1990, Administrative Science Quarterly, 42, pp. 304-338.

Baumol, W. J., Panzar, J. C. \& Willig, R. D. (1982) Contestable Markets and the Theory of Industry Structure (New York, NY: Harcourt Brace Jovanovich).

Bennison, D., Clarke, I. \& Pal, J. (1995) Locational decision making in retailing: An exploratory framework for analysis, The International Review of Retail, Distribution and Consumer Research, 5(1), pp. 120.

Bull, A. O. (1994) Pricing a motel's location, International Journal of Contemporary Hospitality Management, 6(6), pp. 10-15.

Burt, R. S. (1992) Structural Holes (Cambridge, MA: Harvard University Press).

Cadotte, E. R. \& Turgeon, N. (1988) Key factors in guest satisfaction, Cornell Hotel and Restaurant Administration Quarterly, 28(4), pp. 44-51.

Canina, L., Enz, C. \& Harrison, J. (2005) Agglomeration effects and strategic orientations: Evidence from the U.S. lodging industry, The Academy of Management Journal, 48(4), pp. 565-581.

Catrett, J. \& Lynn, M. (1999) Managing status in the hotel industry, Cornell Hotel and Restaurant Administration Quarterly, 40(1), pp. 26-39.

Chung, W. \& Kalnins, A. (2001) Agglomeration effects and performance: A test of the Texas lodging industry, Strategic Management Journal, 22(10), pp. 969-988.

D’Aveni, R. A. (1994) Hypercompetition: Managing the Dynamics of Strategic Maneuvering (New York, NY: The Free Press). 
Danziger, S., Israeli, A. \& Bekerman, M. (2004) Investigating pricing decisions in the hospitality industry using the behavioral process method, Journal of Hospitality and Leisure Marketing, 11(2/3), pp. 5-17.

Enz, C., Canina, L. \& Walsh, K. (2001) Hotel industry averages: An inaccurate tool for measuring performance, Cornell Hotel and Restaurant Administration Quarterly, 42(6), pp. 22-32.

Fischer, J. \& Harrington, J. (1996) Product variety and firm agglomeration, RAND Journal of Economics, 27(2), pp. 281-309.

Greene, W. H. (2000) Econometric Analysis (pp. 465-469, 4th ed.) (Upper Saddle River, NJ: PrenticeHall).

Gonzalez-Benito, O. \& Gonzalez-Benito, J. (2004) Geographic price discrimination as a retail strategy, International Journal of Market Research, 46(4), pp. 443-464.

Hamel, G. (1998) The challenge today: Changing the rules of the game, Business Strategy Review, 9(2), pp. 19-26.

Jaffe, A., Trajtenberg, M. \& Henderson, R. (1993) Geographic localization of knowledge spillovers as evidenced by patent citations, Quarterly Journal of Economics, 108, pp. 579-598.

Hall, D. \& Severini, T. (1998) Extended generalized estimating equations for clustered data, Journal of the American Statistical Association, 93, pp. 1365-1375.Competitive Dynamics and Pricing Behavior in US Hotels 249

Horak, S. (1997) Influence of forested area in hotel vicinity on hotel accommodation prices, Turizam, 45 (5/6), p. 125.

Ingram, P. (1996) Organizational form as a solution to the problem of credible commitment: The evolution of naming strategies among U.S. hotel chains, Strategic Management Journal, 17(Special Issue), pp. 85-98.

Kalnins, A. \& Chung, W. (2004) Resource-seeking agglomeration: A study of market entry in the lodging industry, Strategic Management Journal, 25(7), pp. 689-699.

Karington, K. (2007) Five secrets of site selection, Pizza Today. Retrieved March 2007 from: pizzatoday.com.

Luk, K., Tam, M. \& Wong, S. (1995) Characteristics of magazine advertisements on hotel service: A content analysis, Journal of Travel and Tourism Marketing, 4(3), pp. 29-43.

Marshall, A. (1920) Principles of Economics (London: Macmillan).

Matanovich, T., Lilien, G. \& Rangaswamy, A. (1999) Engineering the price-value relationship, Marketing Management, 8(1), pp. 48-53. 
Mayo, E. (1974) A model of motel-choice, Cornell Hotel and Restaurant Administration Quarterly, 15(3), pp. 55-64.

Mazzeo, M. (2002) Product choice and oligopoly market structure, RAND Journal of Economics, 33(2), pp. 221-242.

Miller, H. (1996) Pricing policy reactions to agglomeration in a market with spatial search, Journal of Regional Science, 36(3), pp. 393-415.

Pantzalis, C. (2001) Does location matter? An empirical analysis of geographic scope and MNC market valuation, Journal of International Business Studies, 32(1), pp. 133-155.

Phelps, N. (2004) Clusters, dispersion and the space in between: For an economic geography of the banal, Urban Studies, 41(5/6), pp. 971-989.

Porter, M. E. (1980) Competitive Strategy: Techniques for analyzing industries and competitors (New York, NY: Free Press).

Porter, M. E. (1985) Competitive Advantage: Creating and sustaining superior performance (New York: Free Press).

Porter, M. E. (1994) The role of location in competition, Journal of Economics of Business, 1(1), pp. 3539.

Porter, M. (1998) Clusters and the new economics of competition, Harvard Business Review, 76(6), pp. 77-90.

Rowell, K. \& Walters, D. (1976) Analyzing data with repeated observations on each experimented unit, Journal of Agricultural Science, 87, pp. 423-432.

Shaver, J. M. (1998) Accounting for endogeneity when assessing strategic performance: Does entry choice affect FDI survival, Management Science, 44, pp. 571-585.

Shaver, J. \& Flyer, F. (2000) Agglomeration economies, firm heterogeneity, and foreign direct investment in the United States, Strategic Management Journal, 21(12), pp. 1175-1193.

Smith, K., Ferrier, W. \& Ndofor, H. (2001) Competitive dynamics research: Critique and future directions. In: M. A. Hitt, R. E. Freeman \& J. S. Harrison (Eds.), Blackwell Handbook of Strategic Management, pp. 315-361 (Oxford: Blackwell Publishers).

Steed, E. \& Gu, Z. (2005) An examination of hotel room pricing methods: Practiced and proposed, Journal of Revenue and Pricing, 3(4), pp. 369-379.

Thrane, C. (2007) Examining the determinants of room rates for hotels in capital cities: The Oslo experience, Journal of Revenue and Pricing Management, 5(4), pp. 315-323. 
Wind, J., Green, P., Shifflet, D. \& Scarbrough, M. (1989) Courtyard by Marriott: Designing a hotel facility with consumer-based marketing models, Interfaces, 19(1), pp. 25-47.

Young, G., Smith, K. G. \& Grimm, C. M. (1996) “Austrian” and industrial organization perspectives on firm-level competitive activity and performance, Organization Science, 7(3), pp. 243-254.250 C. A. Enz et al. 